Article

\title{
Toolkit for Population Health Initiatives Around the Globe Related to Collaborative Comprehensive Medication Management for Children and Youth
}

\author{
Richard H. Parrish II 1,2,*(i) and Johannes van den Anker $3,4,5$ \\ 1 Department of Pharmacy Services, St. Christopher's Hospital for Children-American Academic Health \\ System, 160 E. Erie Avenue, Philadelphia, PA 19134, USA \\ 2 Virginia Commonwealth University, School of Pharmacy, Richmond, VA 23298, USA \\ 3 Universitäts-Kinderspital beider Basel (UKBB), Spitalstrasse 33, CH-4031 Basel, Switzerland; \\ JohannesN.VandenAnker@ukbb.ch \\ 4 Children's National Health System, 111 Michigan Avenue, Washington, DC 20010, USA \\ 5 Erasmus Medical Center-Sophia Children's Hospital, s-Gravendijkwal 230, 3015 CE Rotterdam, \\ The Netherlands \\ * Correspondence: richard.parrish@americanacademic.com
}

Received: 13 February 2019; Accepted: 2 April 2019; Published: 8 April 2019

\begin{abstract}
Almost 30 million babies worldwide are born prematurely or become ill annually and need specialized care to survive. Formalized collaborative practice agreements (CPA) between clinical pharmacists and physicians have been put forward as a means for improving the overall medicating experience in many patient populations, including children. This report briefly describes opportunities for collaboration using examples from countries on each continent where CPA is established in professional governance documents and standards. It also provides resources in the form of a toolkit for countries and pharmacist-physician collaborators to authorize and form CPAs to provide comprehensive medication management (CMM) for children and youth with special health care needs (CSHCN).
\end{abstract}

Keywords: clinical pharmacy; pediatrics; collaboration; population health; comprehensive medication management; children; global

\section{Introduction}

Almost 30 million babies worldwide are born prematurely or become ill annually and need specialized care to survive [1]. The Convention on the Rights of the Child was a clarion call to rethink how care is delivered in hospital and ambulatory environments to the most vulnerable and marginalized children around the world [2]. Unfortunately, one-third of the world's population lack regular access to essential medication [3]. In addition, it has been estimated that $\$ 500$ billion annually could be saved through the responsible use of medication [4]. Moreover, as early as 2006, the World Health Organization (WHO) and the International Pharmaceutical Federation (FIP) recognized the paradigm shift occurring worldwide in the practice of pharmacy and developed a handbook for practitioners, educators, researchers, and policy makers to enable meaningful changes to the scope of the practice [5]. A 2009 FIP statement on collaborative pharmacy practice identified five levels of collaboration, from minimal contact with other health professionals to the authority to initiate or modify pharmacotherapy [6]. The importance of having adequate pharmacy technicians and other pharmacy support staff to allow clinical pharmacists to engage in advanced practice activities cannot be overemphasized [7]. The purpose of this paper is to provide a toolkit for global organizations in the developed and developing world to provide collaborative care (CPA) and comprehensive medication 
management (CMM) for children and youth with special health care needs (CSHCN). To provide specific resources for countries to initiate and sustain collaborative practices and/or networks for providing children's care, this paper has sections focused on different continents.

To estimate whether a particular country has the capacity for CMM through CPA, an internet search was performed using the following search terms: children, pediatrics, clinical pharmacy, collaborative practice, collaborative care, pharmacist prescribing $(\mathrm{PhP})$, partnership for care, board of pharmacy, pharmacy council, pharmacy guild, pharmaceutical society, regulatory, medication review, medication management, medication access, scope of practice, and each continent. While an Internet search may be limited as far as creating a comprehensive survey of practice expectations worldwide, the authors realized that a search of this nature may not capture all possible activity in other countries. In addition, the report was limited to English language websites and those that could be translated. The toolkit provides tools and resources for potential collaborators to assess the value of closer collaboration in practice for the benefit of patients, including children. Moreover, the expansion of clinical pharmacy education within universities may be an indicator of an evolving societal expectation for collaborative CMM practice. Readers are referred to Appendix A for further information about educational standards, especially Fathelrahman et al. The jurisdictional or regulatory documents of the countries listed in this report have a reference to CPA, CMM, or PhP and are profiled in World Health Organization (https://www.who.int/maternal_child_adolescent/child/en/), UNICEF (https://www.unicefusa.org/), International Pharmaceutical Federation (FIP; http://www.fip.nl/), or Commonwealth Fund (https://international.commonwealthfund.org/) publications. Countries listed in this report serve as examples of the scope of regulatory and practice scenarios and processes that could be applied in the developing world. Table S1 provides a continent comparison of the extent to which key clinical pharmacist activities are expected in daily practice [8].

\section{Africa}

In South Africa, pharmacists are registered with the South African Pharmacy Council. While pharmacists in hospital practice may contribute to antimicrobial stewardship programs (e.g., switches from IV to oral administration), provide pharmacokinetic advice (e.g., therapeutic drug monitoring), or service anticoagulant clinics, they are unable to alter doses or order laboratory tests on their own [9]. Domain 5.7 of the 2018 Competency Standards for Pharmacists includes a behavioral statement on collaborative practice in terms of the entry level to practice, intermediate practice, and advanced practice $[10,11]$.

Useful links on collaborative practice and regulation:

- South African Pharmacy Council (SAPC) (https://www.pharmcouncil.co.za/)

- Pharmaceutical Society of South Africa (https://www.pssa.org.za/)

- South African Society of Clinical Pharmacy (https://www.sasocp.co.za/)

\section{Asia}

In Singapore, registration for specialist pharmacists includes advanced pharmacotherapy for cardiology, geriatrics, infectious diseases, and psychiatry. Oncology pharmacy, critical care pharmacy, and pediatric pharmacy are also recognized by the Pharmacy Specialists Accreditation Board. Board certifications from the Board of Pharmacy Specialties (BPS) and case write ups and logs are required for advanced practice [12].

Useful links on collaborative practice and regulation:

- Health Sciences Authority (Registration of Pharmacies; http://www.hsa.gov.sg/content/hsa/ en/Health_Products_Regulation/Manufacturing_Importation_Distribution/Overview/Audit_ Licensing_and_Registration_Of_Pharmacies.html)

- Singapore Pharmacy Council (http://www.healthprofessionals.gov.sg/spc) 
- Therapeutics Products Division (http://www.hsa.gov.sg/content/hsa/en/Health_Products_ Regulation/Western_Medicines/Overview.html)

- Pharmaceutical Society of Singapore (PSS; http://www.pss.org.sg/)

- Pharmacy Specialists Accreditation Board (http://www.healthprofessionals.gov.sg/psab)

\section{Europe}

In the Netherlands, the Charter Professionalism of the Pharmacist governs the ethical and practice standards for collaborating with other health care professionals [13]. The professional context of pharmacists includes collaboration, referred to as the complementarity of pharmacists and physicians. "Physicians and pharmacists play the following roles in the care process: the physician makes a diagnosis and, after discussing the options with the patient, recommends a choice of treatment. The pharmacist then advises on the translation of the treatment into a suitable pharmacotherapy product for the patient". Clearly, the Dutch Minister of Health, Welfare, and Sport and the House of Representatives support "close collaboration" with general practitioners and specialists for advise on medication optimization [14]. A systematic review of non-dispensing pharmacists embedded in primary care practice revealed that fully integrated pharmacists can improve patient-centered care [15]. Recently, the Dutch Pediatric Pharmacotherapy Expertise Network or Nederlands Kenniscentrum voor Farmacotherapie bij Kinderen (NKFK) developed an evidence-based framework for dosing children's medication and combined it with the Dutch Pediatric Formulary [16].

Useful links on collaborative practice and regulation:

- The Royal Dutch Pharmacists Association (https://www.knmp.nl/knmp/about-knmp)

- Kinderformularium (https://www.kinderformularium.nl/)

In the United Kingdom, Standard 2 of the standards for pharmacy professionals of the General Pharmaceutical Council (GPhC) states that pharmacy professionals work in partnership or collaboration with patients and others on the health care team [17]. Just this year, GPhC released standards for the education and training of pharmacist-independent prescribers [18]. In this document, all non-medical prescribers take responsibility for the clinical assessment of the patient; establishing a working diagnosis; and specifying the clinical management required, as well as the responsibility and appropriateness of any prescribing [17]. Medication optimization is a major trend to ensure safer prescribing that is based on shared decision-making, medication review and reconciliation, and optimization of key therapeutic areas (such as antimicrobials) [19].

Useful links for collaborative practice and regulation:

- Medical and Healthcare Products Regulatory Agency (MHRA; https:/www.gov.uk/government/ organisations/medicines-and-healthcare-products-regulatory-agency)

- The European Medicines Agency (http://www.emea.eu/)

- General Pharmaceutical Council (http://www.pharmacyregulation.org/registration/registrationpharmacy-premises)

- Royal Pharmaceutical Society of Great Britain (http://www.rpharms.com/home/home.asp)

- Pharmaceutical Group of the European Union (https://www.pgeu.eu/en/pgeu/members.html)

- British National Formulary for Children (https://about.medicinescomplete.com/publication/britishnational-formulary-for-children/)

\section{Oceania}

In New Zealand, the Pharmacy Council registers pharmacist prescribers that work in a collaborative health team environment and are authorized to initiate, modify, maintain, or discontinue prescription therapy; order and interpret investigations; assess and monitor a patient's response to therapy; and provide education and advice to a patient regarding their therapy [20]. Practice area examples include 
specializing in a therapeutic area, generalist practice in primary care or the emergency department, high risk areas of the continuum of care, and specific classes of medications [21].

Useful links on collaborative practice and regulation:

- Medsafe (http://www.medsafe.govt.nz/)

- Pharmaceutical Society of New Zealand (http://www.psnz.org.nz/)

- Pharmacy Council (http://www.pharmacycouncil.org.nz/index.asp)

- Pharmacy Guild of New Zealand (http://www.pgnz.org.nz/)

In Australia, Standard 9 of the 2017 Professional Practice Standards specifically lists collaborative care, the responsibilities of pharmacists in general practice clinics, the provision of Aboriginal and Torres Strait Islander people, and practice in residential care facilities and medical home practices. Pharmacists also have a responsibility to provide health screenings and risk assessments (Standard 10) for estimating cardiovascular, diabetes, obstructive sleep apnea, and skin cancer risk using standardized tools (see links below). Pharmacists also provide vaccinations (Standard 11), minor ailments service (Standard 12), disease state management (Standard 13), medication review (Standard 14), dose administration aid (Standard 15), and harm minimization (Standard 16) in a collaborative fashion [22].

Useful links on collaborative practice and regulation:

- Therapeutic Goods Administration, Department of Health and Aging (http://www.tga.gov.au/)

- The Pharmacy Guild of Australia (http://www.guild.org.au/)

- The Pharmaceutical Society of Australia (http://www.psa.org.au/)

- International Health Care System Profiles-Australia (https://international.commonwealthfund. org/countries/australia/)

- Clinical Information Access Portal of New South Wales (login required; https://www.ciap.health. nsw.gov.au/browse/paed.html)

\section{South America}

In Brazil, national Resolutions 585/2013 and 586/2013 and Federal Law 13021/2014 changed the classification of pharmacists and established the title of professional specialist for pharmacists in Brazil, which includes the title of specialist in clinical pharmacy [23]. In addition, a clinical services conceptual framework has also been published, and its content modifies what is proposed in the Brazilian Classification of Occupations, particularly with regards to clinical pharmacy [24]. Collaborative practice is in its formative phase with the establishment of the Brazilian Society of Clinical Pharmacy (2017). Pharmacists are independent prescribers for non-prescription medications and dependent prescribers continuously used for refills or therapy previously prescribed by a physician [23]. Like other countries, the lack of mass-produced child-friendly preparations for clinically important products directly affects child health [25].

Useful links on collaborative practice and regulation:

- Brazilian Society of Pharmacists and Community Pharmacies (https://sbffc.org.br/)

- Support Program for Pharmaceutical Care in Healthcare (http://www.cff.org.br/userfiles/file/ _PROFAR_kit_Livro_corrigido.pdf)

- National Health Surveillance Agency (http://portal.anvisa.gov.br/)

\section{Summary}

The purpose of this toolkit is to aid countries and clinical pharmacists around the world in identifying opportunities to develop more formalized collaborative practices between clinical pharmacists and other prescribers for managing the medications of children. Progress related to CMM and CPA in the developed world may be applicable in other jurisdictions and settings. 
Supplementary Materials: Supplementary materials can be found at http://www.mdpi.com/2227-9067/6/4/57/s1.

Author Contributions: Conceptualization, R.H.P.II and J.v.d.A.; writing-original draft preparation, R.H.P.II; writing-review and editing, R.H.P.II, J.v.d.A.; project administration, R.H.P.II.

Conflicts of Interest: The authors declare no conflict of interest.

\section{Appendix A Additional Useful Websites on Collaborative Practice and Regulation}

- IMS Institute for Healthcare Informatics. Advancing responsible use of medicines: applying levers for change. 2012. Available online: http://pharmanalyses.fr/wp-content/uploads/2012/10/ Advancing-Responsible-Use-of-Meds-Report-01-10-12.pdf (accessed 5 April 2019).

- $\quad$ FIP Stakeholder Roundtables-Ensuring more responsible medicines use-the pharmaceutical

- profession takes the lead ensuring more responsible medicines use. 2012 Oct 2\&4; Amsterdam, The Netherlands: International Pharmaceutical Federation. Available online: https://centennial. congress.pharmacy/files/static/FIP_Roundtables_Final.pdf (accessed 23 January 2019).

- European Directorate of the Quality of Medicines \& Healthcare. Pharmaceutical care-policies and practices for a safer, more responsible and cost-effective health system. Strasbourg: Council of Europe; 2012. 62 p. Available online: http://www.edqm.eu/medias/fichiers/policies_and_ practices_for_a_safer_more_responsibl.pdf (accessed 23 January 2019).

- Innovative Medicines Initiative [Internet] European Union. Available online: http://www.imi. europa.eu/ (accessed 23 January 2019).

- Transatlantic Taskforce on Antimicrobial Resistance (TATFAR). [Internet] European Union and United States. Available online: http://ecdc.europa.eu/en/activities/diseaseprogrammes/TATFAR/ Pages/index.aspx (accessed 23 January 2019).

- The evolving threat of antimicrobial resistance-options for action. Geneva: World Health Organization; 2012. ISBN: 9789241503181. Available online: http://whqlibdoc.who.int/ publications/2012/9789241503181_eng.pdf (accessed 23 January 2019).

- Additional Comments from Ministries of Health. Ministers Summit on The Benefits of the Responsible Use of Medicines-setting policies for better, cost-effective healthcare. 2012 Oct 3; Amsterdam, The Netherlands. Available online: http://www.government.nl/ministries/vws (accessed 23 January 2019).

- Fathelrahman, A.; Ibrahim, M.; Wertheimer, A.I. (eds.). Pharmacy Practice in Developing Countries: Achievements and Challenges. London: Elsevier (2016). Available online: https://www.sciencedirect. com/science/article/pii/B9780128017142020013 (accessed 23 January 2019).

- International Pharmaceutical Federation. 2009 FIP Global Pharmacy Workforce Report. Available online: http://apps.who.int/medicinedocs/documents/s16373e/s16373e.pdf (accessed 5 February 2019).

\section{References}

1. World Health Organization. Survive and Thrive: Transforming Care for Every Small and Sick Newborn; Key Findings. WHO/FWC/MCA/18.11. Licence: CC BY-NC-SA 3.0 IGO; World Health Organization: Geneva, Switzerland, 2018; Available online: https://www.unicef.org/every-child-alive/Survive-and-Thrive_KEY_ FINDINGS_FINAL.pdf. (accessed on 22 January 2019).

2. UNICEF. Convention on the Rights of the Child. 4 November 2014. Available online: https://www.unicef. org/crc/index_30160.html. (accessed on 22 January 2019).

3. Revised Procedures for Updating the WHO Model List of Essential Drugs: A Summary of Proposals and Process; World Health Organization: Geneva, Switzerland, 2001; (Working Document EB109/8/Inf.Doc./2). Available online: http://apps.who.int/medicinedocs/documents/s22165en/s22165en.pdf (accessed on 23 January 2019). 
4. IMS Institute for Healthcare Informatics. Draft of Technical Paper for the Ministers Summit 3rd October 2012: The Benefits of Responsible Use of Medicines-Setting Policies for Better and Cost-Effective Healthcare. Available online: https://centennial.congress.pharmacy/files/static/REPORT_MINISTERS_ SUMMIT_-_English_version_final.pdf (accessed on 23 January 2019).

5. Ministers Summit on The Benefits of the Responsible Use of Medicines-Setting Policies for Better, Cost-Effective Healthcare; Ministry of Health, Welfare and Sport: Amsterdam, The Netherlands, 3 October 2012. Available online: www.fip.org/centennial (accessed on 23 January 2019).

6. International Pharmaceutical Federation. Reference Paper on Collaborative Practice. 2009. Available online: https://www.fip.org/www/uploads/database_file.php?id=319\&table_id= (accessed on 12 February 2019).

7. Koehler, T.; Brown, A. A global picture of pharmacy technician and other pharmacy support workforce cadres. Res. Soc. Adm. Pharm. 2017, 13, 271-279. [CrossRef]

8. American College of Clinical Pharmacy. About Clinical Pharmacists. What Do Clinical Pharmacists Do? Available online: https://www.accp.com/about/clinicalpharmacists.aspx. (accessed on 22 March 2019).

9. Gray, A.; Riddin, J.; Jugathpal, J. Health Care and Pharmacy Practice in South Africa. Can. J. Hosp. Pharm. 2016, 69, 36-41. [CrossRef] [PubMed]

10. South African Pharmacy Council. Competency Standards for Pharmacists in South Africa. 59 The Pharmacy Act (53/1974): 2018 Competency Standards for Pharmacists 41621. 2018 Competency Standards for Pharmacists in terms of Section 33(o) of the Pharmacy Act, 53 of 1974. Available online: https://www.pharmcouncil.co.za/ media/default/documents/BN59_2018_Competency_Stds_20180511.pdf (accessed on 28 January 2019).

11. South African Pharmacy Council. Scopes of practice and qualifications for specialist pharmacists. Board Notice 152 of 2014. Gov. Gaz. 2014, 38327, 1-71.

12. Ministry of Health. Government of Singapore. Pharmacy Specialists Accreditation Board. Criteria for Specialist Pharmacist Accreditation. Available online: http://www.healthprofessionals.gov.sg/psab/specialistaccreditation/criteria-for-specialist-pharmacist-accreditation (accessed on 30 January 2019).

13. Royal Dutch Pharmacists Association. Charter Professionalism of the Pharmacist. 2012. Available online: https://www.knmp.nl/professie/professioneel-handelen/handvest-van-de-apotheker-1/charterprofessionalism-of-the-pharmacist (accessed on 31 January 2019).

14. Briefing Paper. Ministers Summit on The Benefits of the Responsible Use of Medicines-Setting Policies for Better, Cost-Effective Healthcare. 3 October 2012; Ministry of Health, Welfare and Sport \& Utrecht WHO Collaborating Centre for Pharmacoepidemiology and Pharmaceutical Policy Analysis: Amsterdam, The Netherlands, 2012. Available online: http://www.government.nl/ministries/vws (accessed on 23 January 2019).

15. Hazen, A.C.M.; de Bont, A.A.; Boelman, L.; Zwart, D.L.M.; de Gier, J.J.; de Wit, N.J.; Bouvy, M.L. The degree of integration of non-dispensing pharmacists in primary care practice and the impact on health outcomes: A systematic review. Res. Social Adm. Pharm. 2018, 14, 228-240. [CrossRef] [PubMed]

16. Van der Zanden, T.M.; de Wildt, S.N.; Liem, Y.; Offringa, M.; de Hoog, M. Dutch Paediatric Pharmacotherapy Expertise Network NKFK (Nederlands Kenniscentrum voor Farmacotherapie bij Kinderen). Developing a paediatric drug formulary for the Netherlands. Arch. Dis. Child. 2017, 102, 357-361. [CrossRef] [PubMed]

17. General Pharmaceutical Council of Great Britain. Standards for Pharmacy Professionals. May 2017. Available online: https:/gallery.mailchimp.com/2a9eeb21f465e0931a30e5d65/files/4bd64f7f-4101-49db-806e6d1715405f47/Council_papers_indpendent_prescribers.pdf (accessed on 28 January 2019).

18. General Pharmaceutical Council of Great Britain. Implementing revised Education and Training Standards for Pharmacist Independent Prescribers. 6 December 2018. Available online: https://www.pharmacyregulation. org/sites/default/files/standards_for_pharmacy_professionals_may_2017_0.pdf (accessed on 28 January 2019).

19. National Institute for Health and Care Excellence (NICE). Guidelines in Practice. Medicines Optimization: Shared Decision-Making with Patients is Key. 2016. Available online: https://pathways.nice.org.uk/pathways/ medicines-optimisation. (accessed on 28 January 2019).

20. Pharmacy Council of New Zealand. Standards and Guidance for Pharmacist Prescribers: Safe and Effective Pharmacy Practice. Available online: https:/www.pharmacycouncil.org.nz/Portals/12/Documents/ prescribers/Pharmacist_Prescriber_Standards_July2013.pdf?ver=2017-02-20-130511-963 (accessed on 28 January 2019).

21. Pharmacy Council of New Zealand. Pharmacist Prescribers. Available online: https://www.pharmacycouncil. org.nz/Portals/12/Documents/prescribers/Pharmacist \%20Prescriber\%20Scope \%20of\%20Practice\%20Logo\% 20update\%20Jan2018.pdf?ver=2018-01-17-094226-357 (accessed on 28 January 2019). 
22. Pharmaceutical Society of Australia. Professional Practice Standards. 2017. Version 5. pp. 52-95. Available online: https://www.psa.org.au/wp-content/uploads/2018/08/Professional-Practice-Standards-v5. pdf (accessed on 12 February 2019).

23. Melo, A.C.; Galato, D.; Maniero, H.K.; Frade, J.C.Q.P.; Palhano, T.J.; da Silva, W.B.; João, W.S.J. Pharmacy in Brazil: Progress and challenges on the road to expanding clinical practice. Can. J. Hosp. Pharm. 2017, 70, 381-390. [CrossRef] [PubMed]

24. Pharmaceutical Services Directly Aimed at the Patient, Family and Community: Contextualization and Conceptual Framework; Conselho Federal de Farmácia: Brasília, Brazil, 2016; Available online: www.cff.org.br/pagina. php?id=778\&menu=778\&titulo=Publica $\%$ C3\%A7\%C3\%B5es (accessed on 23 January 2019).

25. Quirino da Costa, P.; Rey, L.C.; Coelho, H. Lack of drug preparations for use in children. Brazil. J. Pediatr. (Rio J.) 2009, 85, 229-235.

(C) 2019 by the authors. Licensee MDPI, Basel, Switzerland. This article is an open access article distributed under the terms and conditions of the Creative Commons Attribution (CC BY) license (http://creativecommons.org/licenses/by/4.0/). 